BMJ Open Sport \& Exercise Medicine

\title{
Psychosocial stress factors, including the relationship with the coach, and their influence on acute and overuse injury risk in elite female football players
}

Anne Marte Pensgaard, ${ }^{1}$ Andreas Ivarsson, ${ }^{2}$ Agnethe Nilstad, ${ }^{3}$ Bård Erlend Solstad, ${ }^{1}$ Kathrin Steffen ${ }^{3}$

To cite: Pensgaard AM, Ivarsson A, Nilstad A, et al. Psychosocial stress factors, including the relationship with the coach, and their influence on acute and overuse injury risk in elite female football players. BMJ Open Sport \& Exercise Medicine 2018;4:e000317. doi:10.1136/ bmjsem-2017-000317

Accepted 9 February 2018
Check for updates

${ }^{1}$ Department of Coaching and Psychology, Norwegian School of Sport Sciences, Oslo, Norway ${ }^{2}$ Center of Research on Welfare, Health and Sport, Halmstad University, Halmstad, Sweden ${ }^{3}$ Department of Sports Medicine, Oslo Sports Trauma Research Center, Norwegian School of Sports Sciences, Oslo, Norway

Correspondence to Dr Anne Marte Pensgaard; anne. marte.pensgaard@nih.no

\section{ABSTRACT}

Background The relationship between specific types of stressors (eg, teammates, coach) and acute versus overuse injuries is not well understood.

Objective To examine the roles of different types of stressors as well as the effect of motivational climate on the occurrence of acute and overuse injuries.

Methods Players in the Norwegian elite female football league ( $\mathrm{n}=193$ players from 12 teams) participated in baseline screening tests prior to the 2009 competitive football season. As part of the screening, we included the Life Event Survey for Collegiate Athletes and the Perceived Motivational Climate in Sport Questionnaire (Norwegian short version). Acute and overuse time-loss injuries and exposure to training and matches were recorded prospectively in the football season using weekly text messaging. Data were analysed with Bayesian logistic regression analyses.

Results Using Bayesian logistic regression analyses, we showed that perceived negative life event stress from teammates was associated with an increased risk of acute injuries ( $O R=1.23,95 \%$ credibility interval (1.01 to 1.48)). There was a credible positive association between perceived negative life event stress from the coach and the risk of overuse injuries ( $O R=1.21,95 \%$ credibility interval (1.01 to 1.45)).

Conclusions Players who report teammates as a source of stress have a greater risk of sustaining an acute injury, while players reporting the coach as a source of stress are at greater risk of sustaining an overuse injury. Motivational climate did not relate to increased injury occurrence.

\section{INTRODUCTION}

Although elite athletes experience high numbers of both acute and overuse injuries, questions regarding which athletes are at risk remain largely unanswered due to limitations in current risk prediction models. ${ }^{1}$ While the focus often has been to target physiological and biomechanical parameters when investigating risk factors for sports injuries,

\section{What are the new findings?}

- Having teammates as a source of stress was associated with increased risk ( $O R=1.23,95 \% \mathrm{C}$ (1.01 to 1.48)) of acute injuries.

- Having the coach as a source of stress was associated with an increased risk $(\mathrm{OR}=1.21,95 \% \mathrm{C}$ (1.01 to 1.45$)$ ) of overuse injuries.

- Motivational climate does not seem to increase the risk for either acute or overuse injuries.

How might it influence applied coaching practice in the future?

Coaches should pay particularly attention to the psychosocial climate surrounding the female football players in order to help prevent both acute and overuse injuries.

there has also been an increasing interest to examine the potential influence of psychosocial factors. ${ }^{2}$ A recent meta-analysis on the investigation of psychosocial factors and their association to injury risk concluded that high levels of negative life event stress and strong stress responsivity were the two variables that had the strongest associations with injury risk in athletes. ${ }^{3}$ European football studies, involving male elite players and female junior players, have reported high levels of perceived stress to be associated with injury risk. ${ }^{4-6}$ Also among youth players, there was a moderate, positive association between injury risk during the 8 months season and perception of a mastery climate.

So far, most of the published studies on psychosocial risk factors for sport injuries have been focusing on acute injuries. ${ }^{7}$ However, researchers have suggested that there might be different psychosocial risk factors for acute 
versus overuse injuries. According to the Stress and Injury model, it is suggested that acute injuries are related to the athletes' cognitive appraisal of a potentially stressful situation. ${ }^{8}$ On the other hand, risk factors for overuse injuries might be more related to stress responses stemming from lack of recovery. ${ }^{9-11}$ In line with these suggestions, van der Does $e t a l^{11}$ found decreased general recovery to be associated with an increased risk for acute injuries, while decreased sport recovery was a statistically significant risk factor for overuse injuries among elite and subelite team sport players, including both genders.

Focusing on causes of stress responses, environmental factors (eg, interpersonal relationships such as a poor coach-athlete relationship, culture and norms) will have impact on the athletes' stress levels and consequently on the magnitude of the stress responses. ${ }^{79}$ Environmental factors may even have stronger negative impact on elite athletes than intrapersonal stressors, such as self-doubt and negative thoughts. ${ }^{12-15}$ This can be related to the perceived lack of control athletes experience when stress factors stem from the social context surrounding them, rather than their internal thought processes. ${ }^{16}$ Indeed, communication problems between athlete and coach were suggested, by both athletes and coaches, to be a contributing cause to develop overuse injuries. ${ }^{17}$

Given that different types of stressors might have different impact on both players' cognitions and behaviours, it is surprising that previous studies have defined 'stress' in a very broad term. Negative life stress, for example, has been a summary of a diverse range of stressors such as harassments, moving, personal and social conflicts. We believe it can be more useful to break down these stressors into more specific sources. For example, when athletes perceive the coach-athlete relationship to be a source of stress, they experience higher levels of burn-out and fatigue symptoms, and hence are likely more at risk for overuse injuries. ${ }^{18}$ Additionally, when the athlete is neither able nor willing to share his or her current total burden with the coach, there might be an increased risk for insufficient recovery. ${ }^{19}$ Also, when stress is generated from the interaction between teammates, the stressor can be considered to be a daily hassle, and it is interesting to examine if this is the case if the source of stress stems from friends outside of sport also. ${ }^{20}$ In previous studies, daily hassles have been associated with an increased risk of acute injuries due to, for example, poorer cognitive capacity. ${ }^{3}$

To gain more knowledge of what type of stressors and psychosocial environment might increase the risk of sustaining an acute or overuse injury, we aimed to investigate whether three different potential stressors (coach, teammates and friends outside sports) as well as two environmental factors (task climate and ego climate) are related to the risk for acute and overuse injuries in Norwegian elite female football players. We hypothesised that: (a) when the source of stress was related to the interaction with teammates and friends outside sport, we expect an increased risk of acute injuries; (b) when a player perceived her relationship with her coach to be a source of stress, she would be at increased risk for overuse injuries; (c) a task climate would be related to an increased risk for acute injuries and an ego climate would be related to an increased risk for overuse injuries.

\section{METHODS}

\section{Study design and participants}

Data included in the current study were collected as part of a prospective cohort study assessing potential demographic, neuromuscular, biomechanical, anatomical and genetic risk factors for an ACL injury in elite female handball and football players. ${ }^{21}$ All players expected to play in the Norwegian premier football league in the 2009 season were eligible for participation for this study. The screening tests were conducted at the Norwegian School of Sport Sciences during preseason (February through March 2009). As part of the comprehensive screening, we also asked the players to complete a questionnaire to collect data on demographics and elite playing experience. To assess psychosocial factors as potential risk factors for injury occurrence, we included two surveys.

\section{Perceived stress}

To measure players' life history stressors we used the Life Event Survey for Collegiate Athletes. ${ }^{22}$ This questionnaire comprises a list of 69 events, of which the players were asked whether they had experienced any of these during the previous 12 months, and then to rate the experience of these stressors. The rating is based on an eight-point Likert scale, ranging from 'extremely negative' $(-4)$ to 'extremely positive' $(+4)$. The first author, highly experienced in both research and applied work within sport and exercise psychology, constructed three subscales based on the content of type of stressors and the scales were: (a) perceived negative life event stress from the coach (NLES-Coach) (five items, ie, Communication problems with the coach), (b) perceived negative life event stress from teammates (NLES-Team), (seven items, ie, Conflict with a teammate) and (c) perceived negative life event stress from friends (NLES-Friend) (three items, ie, Major changes with relations to a friend). These suggested subscales were then discussed with the second and fourth authors, who also have extensive experiences of both research and applied work within sport and exercise psychology.

\section{Motivational climate}

We used the Perceived Motivational Climate in Sport Questionnaire (the Norwegian short version) to assess the players perceptions of the motivational climate within their team. ${ }^{23} \mathrm{~A}$ total of six items reflect an ego-oriented climate (ie, the coach favours some players over others), while five items reflect a task-oriented climate (ie, we try to learn new skills). The rating is based on a five-point Likert scale, ranging from 'Strongly disagree' (1) to 'Strongly agree' (5). A mean score is calculated for the two subscales. 


\section{Injury registration}

We recorded all injuries that occurred throughout the 2009 competitive football season (April-November). An injury was recorded if the player was unable to fully participate in football training or match play for at least 1 day beyond the day of injury (time-loss injury). ${ }^{24}$ The player was considered injured until declared fit for full participation in training and available for match selection by the medical staff.

The players individually reported all injuries and exposure throughout the season using text messaging. The registration was conducted on a weekly basis with three text messages sent to the player at the end of each week with questions related to match and training exposure, and time-loss injuries. If an injury was reported, the player was contacted by a physiotherapist to complete a standardised telephone interview on the injury circumstances. Information captured included injured body part, location and type of injury, including a diagnosis using the The Orchard Sports Injury Classification System, injury severity, measured as number of days of absence from play, type of activity (match vs training) and playing surface at injury occurrence. ${ }^{25}$ The data collection procedure has been described in detail and validated in a previous report. ${ }^{26}$

The Regional Committee for Medical Research Ethics, South-Eastern Norway Regional Health Authority and the Norwegian Social Science Data Services approved the study. Players signed a written informed consent form before inclusion, including parental consent for players aged $<18$ years.

\section{Data analysis}

\section{Descriptive statistics}

We conducted the descriptive analyses using the JASP software package. ${ }^{27}$ Data on player demographics are presented as means \pm SDs, including ranges. We calculated individual exposure data as the total hours of training and match play during the season, and missing data were imputed as mean values. Injury rates are reported as the number of injuries per 1000 player hours with 95\% CIs using z statistics.

We applied Bayesian correlation analyses to investigate the relationships between the three stress variables and the two motivational climate variables. For each of the pairwise comparisons a Bayes Factor (BF) was calculated. In line with previous recommendations a $\mathrm{BF}$ above 10 was determined to be evidential. ${ }^{28}$

\section{Bayesian logistic regression analyses}

Prior to the main analyses we performed Bayesian t-tests to investigate potential differences in the three stress variables (coach, teammates and friends), as well as the two motivational climate variables (task and ego), between the players reporting just one type of injury (ie, acute or overuse) and the players reporting both type of injuries during the season. Before we conducted these tests the injured players were divided into four groups: (a) players who experienced only acute injuries $(n=91)$, (b) players who reported at least one overuse injury before an acute injury $(n=13)$, (c) players who reported only overuse injuries $(n=35)$ and $(d)$ players who reported at least one acute injury before an overuse injury $(n=20)$. We performed Bayesian t-tests between the following groups: groups (a) and (b) and groups (c) and (d). Because one player, potentially, could be classified into the injury groups for both type of injuries we wanted to test if there were any differences in the listed variables between those who experienced one injury type prior to the other injury type with those who only experienced one injury type. Also for these analyses $\mathrm{BF}>10$ was determined to be evidential. The tests showed no evidence for a difference between the groups in any of the variables $(\mathrm{BF}<10)$.

To test whether the baseline scores of the psychosocial variables were associated to an increased injury risk, we performed two binary logistic regression analyses with acute and overuse injuries as separate outcome measures, using the Bayesian estimator in Mplus v.7.4. ${ }^{29}$ In both regression models, the three stress variables (coach, teammates and friends), as well as the two motivational climate variables (task and ego), were included as independent variables. The reason for testing two models, one for each injury type, was that previous research has suggested that acute and overuse injuries might be related to different psychological risk factors. ${ }^{11}$ In addition, Markov chain Monte Carlo (MCMC) simulation procedures with a Gibbs sampler were used to generate multiple combined parameter values (ie, credible parameter values). These generated parameter values are used to interpret the posterior probability of a parameter value. ${ }^{30}$

All models were run with 100000 iterations $(50000$ burn-in by default), and every 10 th iteration was used to reduce autocorrelation between MCMC draws. A potential scale reduction factor around 1 was considered as evidence of convergence. ${ }^{31}$ Model fit of the models was assessed using the posterior predictive $\mathrm{P}$ value and the 95\% CI. Indeed, Muthén and Asparouhov ${ }^{31} 32$ argued that 'the $95 \% \mathrm{CI}$ is produced for the difference in the $\mathrm{f}$ statistic for the real and replicated data. A positive lower limit is in line with a low posterior predictive $\mathrm{P}$ value and indicates poor fit' (p315).

For each parameter estimated within the analyses, a credibility interval was calculated. In contrast to the frequentist CI, the credibility interval allows the researcher to calculate an interval that indicates the probability (eg, 95\%) that the parameter of interest lies between the two values given the observed data. ${ }^{32}{ }^{32}$ To gain a deeper understanding of the fundamentals of Bayesian statistics, interested readers are referred to other publications. ${ }^{33} 34$

For the structural paths (ie, the paths specified between the dependent and independent variables) we used informative priors, obtained from previous studies (for specific priors for each path see table 1). We decided to use low precise priors (ie, variances of 0.05 ) to reflect the uncertainty in the priors for the specific population. ${ }^{35}$ 
Table 1 Information about priors, standardised parameter estimates and OR with 95\% credibility interval from the statistical tests

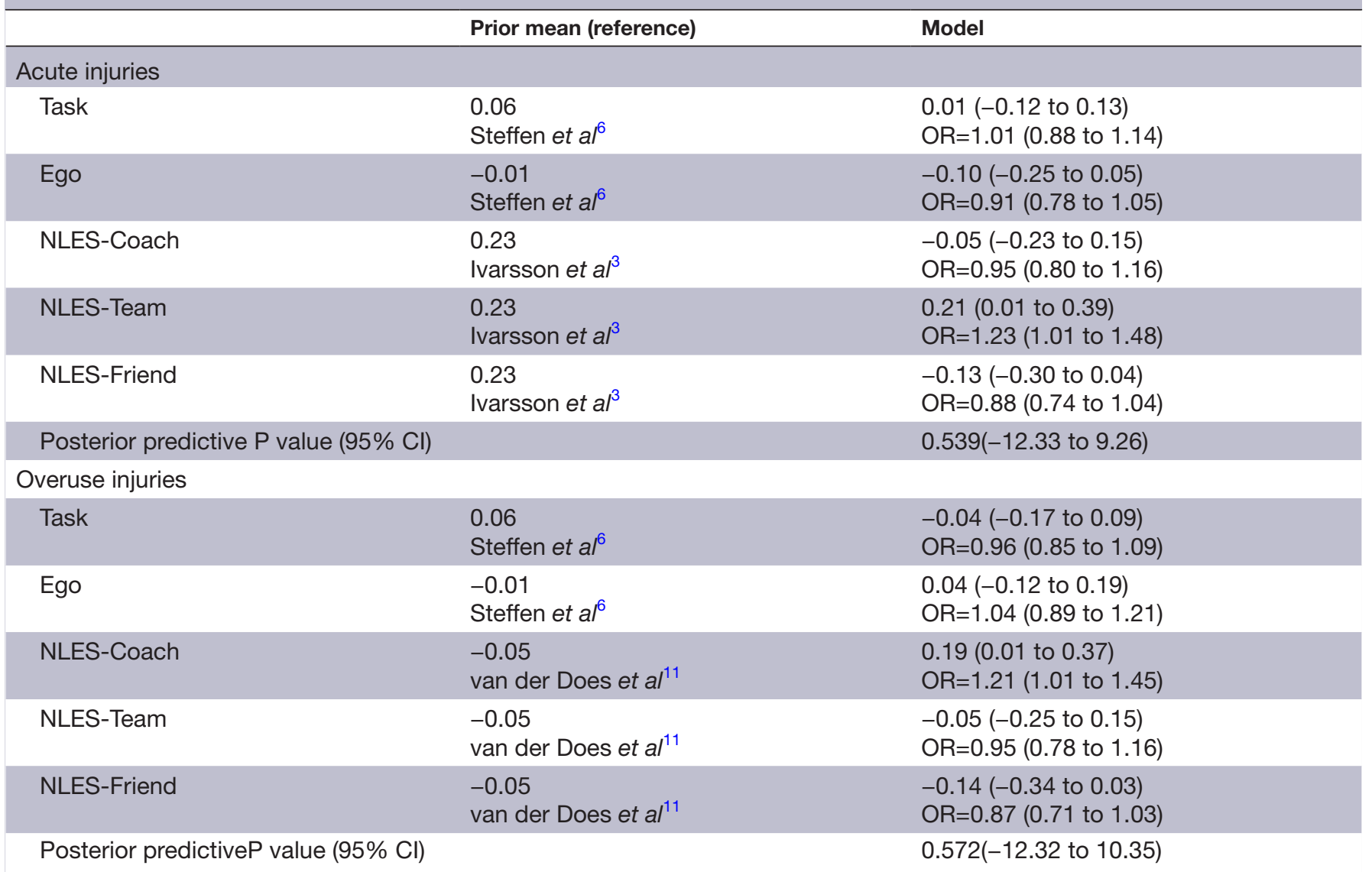

NLES-Coach, negative life event stress from the coach; NLES-Friend, negative life event stress from friends; NLES-Team, negative life event stress from teammates.

Also, for all structural paths we calculated ORs with corresponding $95 \%$ credibility intervals. These calculations were, as proposed by Broemeling, ${ }^{36}$ based on the posterior standardised parameter estimates. ${ }^{36}$ The ORs are presented in table 1 .

\section{RESULTS}

On average, the 193 players were 21.6 years old $(\mathrm{SD}=4.2)$, started playing at elite level at the age of 18 (range 14-33 years) and had played 3.5 seasons at the elite level (range $0-15$ years) at the time of baseline screening tests.

During the 2009 football season (April-November) these players suffered from 164 acute and 69 overuse injuries. Based on a total of 46200 training and match hours these figures correspond to 3.6 (95\% CI 3.0 to 4.1 ) acute and 1.5 (95\% CI 1.1 to 1.8 ) overuse injuries per 1000 playing hours. More than half of the players $(n=104$ players, 54\%) reported at least one acute injury and almost one-third ( $\mathrm{n}=55$ players, $29 \%$ ) at least one overuse injury during the 8 months season.

Prior to season start, the players experienced high levels of task climate and low levels of negative life event stress (table 2). We found strong evidence $(\mathrm{BF}>10)$ for the positive relationship between perceived NLES-Team and NLES-Coach $(r=0.39)$. Also, we found str ong evidence for the negative relationship between perceived NLESTeam and perceived task climate $(\mathrm{r}=-0.22)$. We also found strong evidence for a positive correlation between ego climate and perceived NLES-Coach $(\mathrm{r}=0.24)$. For all correlation estimates see table 3 .

\section{Psychosocial factors and acute injury risk}

The model indicated a good fit between the proposed model and the empirical data (posterior predictive $\mathrm{P}$ value $=0.539,95 \%$ CI $(-12.33$ to 9.26$))$. Perceived motivational climate (ie, ego-oriented climate and task-oriented climate), and history of stressors related to: (a) the coach, (b) teammates and (c) friends explained in total $8 \%$ of the variance in the dependent categorical variable, injury group. Perceived NLES-Team was the only factor that was credibly associated with the probability of reporting at least one acute injury during the season $(\beta=0.21,95 \%$ credibility interval $(0.01,0.39)$, $\mathrm{OR}=1.23,95 \%$ credibility interval (1.01 to 1.48$)$ ). None of the other independent variables were associated with injury risk. For all parameter estimates see table 1.

\section{Psychological risk factors for overuse injuries}

In the second estimated model performed to investigate the potential association between psychosocial factors 
Table 2 Mean and SD of climate measures (task and ego) and sources of stress (coach, friends and teammates), and age of all players

\begin{tabular}{|c|c|c|c|c|c|c|}
\hline & \multicolumn{2}{|l|}{$\begin{array}{l}\text { Full sample } \\
(n=193)\end{array}$} & \multirow{2}{*}{$\begin{array}{l}\text { No acute injury } \\
\text { (n=89) }\end{array}$} & \multirow{2}{*}{$\begin{array}{l}\begin{array}{l}\text { Acute injury } \\
(n=104)\end{array} \\
M(S D)\end{array}$} & \multirow{2}{*}{$\begin{array}{l}\text { No overuse injury } \\
\text { (n=138) }\end{array}$} & \multirow{2}{*}{$\begin{array}{l}\begin{array}{l}\text { Overuse injury } \\
\text { (n=55) }\end{array} \\
M(S D)\end{array}$} \\
\hline & M (SD) & Range & & & & \\
\hline Task climate & $4.5(0.5)$ & $2.8-5.0$ & $4.5(0.5)$ & $4.5(0.5)$ & $4.5(0.5)$ & $4.4(0.5)$ \\
\hline Ego climate & $3.1(0.8)$ & $1.33-4.5$ & $3.2(0.7)$ & $3.6(0.6)$ & $3.1(0.7)$ & $3.2(0.8)$ \\
\hline NLESCoach & $1.3(2.6)$ & $0.0-16.0$ & $1.4(2.5)$ & $1.3(2.6)$ & $1.1(2.2)$ & $1.9(3.3)$ \\
\hline NLES-Friend & $0.4(1.1)$ & $0.0-7.0$ & $0.6(1.3)$ & $0.1(0.8)$ & $0.5(1.2)$ & $0.3(0.8)$ \\
\hline NLES-Team & $0.9(1.8)$ & $0.0-8.0$ & 0.7 (1.4) & $1.1(2.1)$ & $0.9(1.9)$ & $1.0(1.8)$ \\
\hline Age & $21.6(4.2)$ & $16.0-37.0$ & 21.2 (3.8) & $21.9(4.6)$ & $21.1(4.2)$ & $22.7(4.0)$ \\
\hline
\end{tabular}

NLES-Coach, negative life event stress from the coach; NLES-Friend, negative life event stress from friends; NLES- Team, negative life event stress from teammates.

and the risk of experiencing at least one overuse injury during the season, the same independent variables were included into the model as for acute injuries. The model indicated a good fit to data (posterior predictive $\mathrm{P}$ value $=0.572,95 \%$ CI $(-12.32$ to 10.35$)$ ), showing a good match between the specified model and the empirical data. Also in this analysis, the independent variables (task, ego and the three categories of history of stressors) could together explain $8 \%$ of the variance in the dependent categorical variable, injury group. Perceived NLES-Coach had a credible positive association with the probability of reporting at least one overuse injury during the season $(\beta=0.19,95 \%$ credibility interval (0.01 to 0.37$), \mathrm{OR}=1.21,95 \%$ credibility interval ( 1.01 to $1.45)$ ). No other associations were found. For all parameter estimates see table 1 .

\section{DISCUSSION}

To our knowledge, this is the first study to investigate how different sources of perceived negative stress may increase the risk of different types of injuries. In a large cohort of Norwegian elite female football players, the chance of sustaining an acute injury during the season increased when the source of stress predominantly was associated with conflicts with teammates. However, when the coach was perceived as the source of stress, these athletes had a greater risk for overuse injuries. Our

\begin{tabular}{|c|c|c|c|c|}
\hline 1 & 2 & 3 & 4 & 5 \\
\hline 1. Task & -0.18 & -0.13 & -0.10 & $-0.22^{*}$ \\
\hline 2. Ego & & $0.24^{*}$ & 0.10 & 0.20 \\
\hline 3. NLES-Coach & & & 0.18 & $0.39^{*}$ \\
\hline 4. NLES-Friend & & & & 0.21 \\
\hline 5. NLES-Team & & & & \\
\hline
\end{tabular}

${ }^{*} \mathrm{BF}>10$

NLES-Coach, negative life event stress from the coach;

NLES-Friend, negative life event stress from friends; NLES-

Team, negative life event stress from teammates. results therefore support Ekstrand et a ${ }^{37}$ who found that a transformational leadership style was correlated with smaller numbers of severe injuries among male football players.

\section{Acute injury risk}

Andersen and Williams ${ }^{8}$ suggested that stress can increase risk of acute injuries via cognitive features (attentional perturbations such as peripheral narrowing) thought to predispose an athlete to injury. When teammates are seen as a source of stress, additional mechanisms, such as depression, frustration or anger, may further contribute to players injuring themselves as well as other players, as for example through deliberate foul play. ${ }^{38} 39$ The latter has not been the scope of much attention, but needs to be investigated further.

While conflict with teammates seems to lead to an increased risk of having an acute injury, this is not the case when the source of stress is rooted in problems with friends outside of sports. As these elite-level athletes in their early 20es spend a considerable amount of time together with their teammates during both training and matches, their relationships within the sporting context seem to play a more important role than relationships outside sport; that would be consistent with our findings. ${ }^{40}$ Thus, because the overall explained variance of acute injuries is rather low, we need to consider other reasons why acute injuries occur.

\section{Overuse injury risk}

Overuse injuries have generally been described to be a result of repeated microtrauma with no single, identifiable cause. ${ }^{24}$ However, in the Biopsychosocial Model of Stress Athletic Injury and Health, which is an independent expansion of the classic stress-injury model, the developers suggest that the relationship between psychosocial stress and athletic injury appears even stronger for overuse injuries. $^{840}$ More specifically, overuse injuries are, in comparison to acute injuries, suggested to be less dependent on cognitive processing and more likely related to physiological processes affecting training adaptation and recovery. 
Our findings that show that a perceived conflict with the coach seems to be a notable factor with regard to overuse injuries, support this claim. Players who have difficulties communicating with their coach may under-report pain and emerging injuries to avoid increasing the conflict further. ${ }^{41}$ From the coach's perspective, it may be difficult to interpret the signals from the player and thus, the coach may perceive lack of effort as a sign of silent protest and not a way for the player to reduce impact or load.

Our findings extend the findings reported by van Wilgen and Verhagen. ${ }^{17}$ In their qualitative study of both athletes $(n=9)$ and coaches $(n=9)$ from a range of different sports, both groups expressed that communication problems between the athlete and the coach were important risk factors for overuse injuries. However, our results strongly encourage more in-depth knowledge into these mechanisms to reduce the burden of overuse injuries. The moderate correlation between reporting an ego-oriented climate and perceiving the coach as a source of stress confirms the findings from previous studies involving elite-level athletes, but there was no direct link to injury occurrence, suggesting an indirect effect where it is the conflict with the coach itself that is the problem, and not the perceived climate. ${ }^{15}$ Perceiving a task-oriented climate did not relate to increased risk of injury in our study, which is in contrast to the findings of Steffen et $a t^{6}$ among female youth football players. However, that study did not look into acute versus overuse injuries, which may explain parts of this difference. In our study, there was a significant, negative correlation between a task-oriented climate and reporting teammates as a source of stress. This extends findings of studies which report that perceived social support can be a buffer when it comes to getting injured. ${ }^{42}$ Furthermore, it encourages us to continue trying to get a more comprehensive understanding of the role of environmental sources of stress among elite athletes.

\section{Methodological considerations}

We performed all analyses based on the Bayesian paradigm of statistics, which has a number of advantages over the more traditional frequentist statistics. ${ }^{43} 44$ Although Bayesian methods are better equipped to model data with small sample sizes, estimates are highly sensitive to the specification of the prior distribution. ${ }^{45}$ To decrease potential bias in the selection process, we used prior estimates from one meta-analysis and two empirical studies (for estimates that were not included in the meta-analysis). Low precise priors, however, were specified for the variances on the structural parameters to reflect the uncertainty in the priors for the specific population. $^{34}$

Another strength of the current study is its prospective cohort design and its homogenous sample of elite female football players from 12 different teams. These athletes were all part of a highly competitive climate to maintain their position on in the team roster. The use of a validated injury registration method and the clinical verification of each of the injuries by a physiotherapist within 1 week of occurrence was another strength of this study. ${ }^{25}$

We recognise that in many cases, athletes continue to train and compete with reduced performance, in fear of telling a coach about an emerging injury for fear of losing their position on the team. ${ }^{46}$ We used the traditional time-loss injury definition measuring the severity of injuries by the players' absence from play ${ }^{24}$ and not the newly developed method for the registration of overuse injuries. ${ }^{47}$ We thereby may have underestimated the presence of overuse injuries in the current cohort.

\section{Clinical implications and summary}

Coaches should prioritise having an ongoing and mutually trusting communication with their players, allowing the players feeling safe to express how they feel. Further, players themselves should be aware that they increase the risk of being injured if there is a conflict with their teammate and could be taught self-regulation techniques in order to cope better in such situations. ${ }^{48}$

This prospective cohort study in Norwegian elite female football players revealed that the source of stress was interacting differently with injury types. While conflict with teammates was associated with an increased risk for acute injuries, players who reported the coach as the source of stress had a greater risk for overuse injuries. There was a positive association between an ego climate and the coach as a source of stress. Perceiving a task-oriented climate did not relate to increased risk of injury, which is in contrast to findings among female youth football players.

Contributors AMP, Al, AN, BES and KS contributed to the study design and data recoding preparation. AN and KS were responsible for the data collection, while all authors contributed to data analysis. AMP wrote the first draft. All authors contributed to the final paper.

Funding This research received no specific grant from any funding agency in the public, commercial or not-for-profit sectors.

\section{Competing interests None declared.}

Ethics approval The Regional Committee for Medical Research Ethics, SouthEastern Norway Regional Health Authority and the Norwegian Social Science Data Services approved the study.

Provenance and peer review Not commissioned; externally peer reviewed.

Open Access This is an Open Access article distributed in accordance with the Creative Commons Attribution Non Commercial (CC BY-NC 4.0) license, which permits others to distribute, remix, adapt, build upon this work non-commercially, and license their derivative works on different terms, provided the original work is properly cited and the use is non-commercial. See: http://creativecommons.org/ licenses/by-nc/4.0/

(C) Article author(s) (or their employer(s) unless otherwise stated in the text of the article) 2018. All rights reserved. No commercial use is permitted unless otherwise expressly granted.

\section{REFERENCES}

1. Bahr R. Why screening tests to predict injury do not workand probably never will...: a critical review. Br J Sports Med 2016;50:776-80.

2. Almeida PL, Olmedilla A, Rubio VJ. Psychology in the realm of sport injury: what it is all about. Rev Psicol Deporte 2014;23:395-400.

3. Ivarsson A, Johnson U, Andersen MB, et al. Psychosocial factors and sport injuries: meta-analyses for prediction and prevention. Sports Med 2017;47:353-65. 
4. Ivarsson A, Johnson U. Psychological factors as predictors of injuries among senior soccer players. A prospective study. J Sports Sci Med 2010;9:347-52.

5. Ivarsson A, Johnson U, Lindwall M, et al. Psychosocial stress as a predictor of injury in elite junior soccer: a latent growth curve analysis. J Sci Med Sport 2014;17:366-70.

6. Steffen K, Pensgaard AM, Bahr R. Self-reported psychological characteristics as risk factors for injuries in female youth football. Scand J Med Sci Sports 2009;19:442-51.

7. Johnson U, Ivarsson A. Psychosocial factors and sport injuries: prediction, prevention and future research directions. Curr Opin Psychol 2017;16:89-92.

8. Andersen MB, Williams JM. A model of stress and athletic injury: prediction and prevention. J Sports Med Exerc Psychol 1988;10:294-306.

9. Richardson SO, Andersen MB, Morris T. Overtraining athletes: personal journeys in sport. Champaign, IL: Human Kinetics, 2008.

10. Tranaeus U, Johnson U, Engström B. Psychological antecedents of overuse injuries in Swedish elite floorball players. Athl Insight 2014;6:155-72.

11. van der Does HT, Brink MS, Otter RT, et al. Injury risk is increased by changes in perceived recovery of team sport players. Clin J Sport Med 2017;27:46-51.

12. Mellalieu SD, Neil R, Hanton S, et al. Competition stress in sport performers: stressors experienced in the competition environment. $J$ Sports Sci 2009;27:729-44.

13. Pensgaard AM. The dynamics of motivation and perceptions of control when competing in the Olympic Games. Percept Mot Skills 1999;89:116-25.

14. Pensgaard AM. Consulting under pressure: How to help an athlete deal with unexpected distracters during Olympic Games 2006. Int J Sport Exerc Psychol 2008;6:301-7.

15. Pensgaard AM, Roberts GC. The relationship between motivational climate, perceived ability and sources of distress among elite athletes. $J$ Sports Sci 2000;18:191-200.

16. Pensgaard AM, Ursin H. Stress, control, and coping in elite athletes. Scand J Med Sci Sports 1998;8:183-9.

17. van Wilgen $\mathrm{CP}$, Verhagen EA. A qualitative study on overuse injuries: the beliefs of athletes and coaches. J Sci Med Sport 2012;15:116-21.

18. Isoard-Gautheur S, Trouilloud D, Gustafsson H, et al. Associations between the perceived quality of the coach-athlete relationship and athlete burnout: An examination of the mediating role of achievement goals. Psychol Sport Exerc 2016;22:210-7.

19. Eklund RC, Defreese JD. Athlete burnout: what we know, what we could know, and how we can find out more. Int J App Sports Sci 2015;27:63-75.

20. Kontos AP, risk P. Perceived risk, risk taking, estimation of ability and injury among adolescent sport participants. $J$ Pediatr Psychol 2004;29:447-55.

21. Krosshaug T, Steffen K, Kristianslund E, et al. The vertical drop jump is a poor screening test for ACL injuries in female elite soccer and handball players: a prospective cohort study of 710 athletes. Am J Sports Med 2016;44:874-83.

22. Petrie TA. Psychosocial antecedents of athletic injury: the effects of life stress and social support on female collegiate gymnasts. Behav Med 1992;18:127-38.

23. Ommundsen Y, Lemyre PN, Abrahamsen F. Motivational climate, need satisfaction, regulation of motivation and subjective vitality: a study of young soccer players. Int J Sport Psychol 2010;41:216-42.
24. Fuller CW, Ekstrand J, Junge A, et al. Consensus statement on injury definitions and data collection procedures in studies of football (soccer) injuries. Scand J Med Sci Sports 2006;16:83-92.

25. Nilstad A, Andersen TE, Bahr R, et al. Risk factors for lower extremity injuries in elite female soccer players. Am J Sports Med 2014; 42:940-8.

26. The JASP Team2017https://jasp-stats.org

27. Etz A, Vandekerckhove J. A Bayesian perspective on the reproducibility project: psychology. PLoS One 2016;11:e0149794

28. Muthén B2010Bayesian analysis in Mplus: a brief introductionhttp:// www.statmodel.com

29. Kruschke JK. Bayesian estimation supersedes the t test. J Exp Psychol Gen 2013;142:573-603.

30. Kaplan D, Depaoli S. Bayesian structural equation modeling. Hoyle R, Handbook of structural equation modeling. New York: Guilford Press, 2012:650-73.

31. Muthén B, Asparouhov T. Bayesian structural equation modeling: a more flexible representation of substantive theory. Psychol Methods 2012;17:313-35.

32. Van de Shoot R, Depaoli S. Bayesian analyses: where to start and what to report. Eur Health Psychol 2014;16:75-84.

33. Zyphur MJ, Oswald FL. Bayesian estimation and inference: a user's guide. J Manag 2015;41:390-420.

34. Yuan Y, MacKinnon DP. Bayesian mediation analysis. Psychol Methods 2009;14:301-22.

35. Elliot DL, Goldberg L, Kuehl KS. Young women's anterior cruciate ligament injuries. Sports Medicine 2010;40:367-76.

36. Broemeling LD. Bayesian methods in epidemiology. Boca Ranton, FL: Taylor \& Francis, 2014.

37. Ekstrand J, Lundqvist $D$, Lagerbäck $L$. Is there a correlation between coaches' leadership styles and injuries in elite football teams? A study of 36 elite teams in 17 countries. Br J Sports Med 2017;0:1-6.

38. Wiese-Bjornstal DM. Sport injury and college athlete health across the lifespan. J Intercolleg Sport 2009;2:64-80.

39. Gould D, Dieffenbach K, Moffett A. Psychological characteristics and their development in Olympic champions. J Appl Sport Psychol 2002;14:172-204.

40. Appaneal RN, Perna FM. Biopsychosocial model of injury. In: Eklund R, Tenenbaum G, Encyclopedia of sport and exercise psychology. Thousand Oaks: SAGE Publications, Inc, 2014:74-7.

41. Roderick M, Waddington I, Parker G. Playing hurt - managing injuries in English professional football. Int Rev Soc sport 2000;35:165-80.

42. Junge A. The Influence of Psychological Factors on Sports Injuries. Am J Sports Med 2000;28(5_suppl):10-15.

43. Ivarsson A, Andersen MB, Stenling A, et al. Things we still haven't learned (so far). J Sport Exerc Psychol 2015;37:449-61.

44. Stenling A, Ivarsson A, Johnson U. An illustrative example of Bayesian structural equation modeling: the sport motivation scale II. J Sport Exerc Psychol 2015;37:410-20.

45. McNeish D. On using Bayesian methods to address small sample problems. Struct Equ Modeling 2016;23:750-73.

46. Bahr R. No injuries, but plenty of pain? On the methodology for recording overuse symptoms in sports. Br J Sports Med 2009;43:966-72.

47. Clarsen B, Myklebust G, Bahr R. Development and validation of a new method for the registration of overuse injuries in sports injury epidemiology: the Oslo Sports Trauma Research Centre (OSTRC) overuse injury questionnaire. Br J Sports Med 2013;47:495-502.

48. Hagger MS, Chatzisarantis NLD, Griffin M, et al. Injury representations, coping, emotions, and functional outcomes in athletes with sports-related injuries: a test of self-regulation Theory. J Appl Soc Psychol 2005;35:2345-74. 